\title{
CD30 CAR-expressing Autologous T Lymphocytes
}

National Cancer Institute

\section{Source}

National Cancer Institute. CD30 CAR-expressing Autologous T Lymphocytes. NCI

Thesaurus. Code C116738.

A preparation of autologous T-lymphocytes that have been genetically modified to express a chimeric antigen receptor (CAR) specific for the CD30 antigen, with potential immunostimulating and antineoplastic activities. Upon administration, the CD30 CARexpressing autologous T-lymphocytes specifically recognize and bind to CD30expressing tumor cells, resulting in tumor cell lysis. CD30, a cell surface receptor and a member of the tumor necrosis factor (TNF) receptor superfamily, is transiently expressed on activated lymphocytes and is constitutively expressed in hematologic malignancies. 